\section{Personal Sanitario y Pandemia COVID-19 en Chile: Desafíos en Salud Mental}

\section{Health workers and COVID-19 Pandemic in Chile: Mental Health Challenges}

\section{Señor Editor:}

La actual pandemia COVID-19 en Chile implica múltiples desafíos para la población general y, particularmente, para el personal sanitario, dados sus niveles de exposición al virus y de sobrecarga laboral. Ello representa una importante demanda para su salud mental.

Los profesionales de la salud enfrentan situaciones de alto nivel de estrés emocional en períodos de pandemia, tal como lo indica evidencia de épocas relativamente recientes, en los casos de Ébola o el SARS ${ }^{1}$. En esos escenarios, se constataron mayores niveles de estrés en el inicio, durante y luego de controlada la pandemia, además de sintomatología depresiva y ansiosa, así como insomnio, negación, ira y miedo.

Lo anterior también ocurre hoy con COVID-19, siendo más marcada la sintomatología cuando existe trato directo en el cuidado de pacientes con COVID-19, habiendo un mayor riesgo de presentar síntomas de estrés post traumático. El malestar psíquico puede afectar la atención, comprensión y la capacidad de toma de decisiones, implicando un efecto deletéreo en su bienestar general ${ }^{2}$.

El impacto en la salud mental en el personal sanitario es especialmente marcado cuando se enfrentan procesos de toma de decisiones respecto del tipo de tratamiento y su receptor, en situaciones de escasez de recursos, ocasiones en que se ponen en juego los principios clínicos y éticos del ejercicio profesional ${ }^{2,3}$. Una de las preocupaciones principales es el miedo de contagio por falta de insumos de seguridad. Ello, sumado a la pérdida de sensación de orden y control, favorecería la aparición de burnout.
Frente a la problemática de salud mental que ya se está presentando en el personal sanitario en Chile, es necesario plantear respuestas institucionales respecto a la contingencia COVID-19. A partir de una revisión rápida de la literatura, diversas estrategias fueron identificadas (Figura 1), a nivel internacional ${ }^{3-6}$, en relación con la prevención y promoción de la salud mental de los profesionales de la salud, respecto a la pandemia, cuya consideración puede enriquecer el enfrentamiento de esta problemática en Chile.

En general, se propone un abordaje en base a intervenciones psico-sociales multidimensionales y articuladas que consideran comité responsable, apoyo psicológico, mejoría en gestión de personal y capacitaciones sobre manejo técnico de la situación COVID-193-6. El contar con espacios de apoyo entre profesionales, primeros auxilios psicológicos y acceso a la atención profesional sería de ayuda para prevenir y acompañar a las y los profesionales de la salud en los procesos de confusión y miedo propios de su trabajo, en este contexto. Aún más, el apoyo social entre colegas y las jefaturas se conforma como factor protector para la mantención de la salud mental, por lo que debiera promoverse tanto dentro como fuera del espacio laboral.

Complementariamente, se ha visto que medidas muy concretas de soporte psicológico pueden ser de ayuda. Por ejemplo, algunos hospitales en otros países han implementado intervenciones que incluyeron técnicas de relajación, líneas telefónicas de soporte psicológico y dinámicas de apoyo mutuo con favorables resultados. El uso de tecnologías, como Apps y plataformas computacionales, también podría tener un $\mathrm{rol}^{5}$. Las recomendaciones actuales concuerdan en la necesidad de generar procesos de apoyo rutinario, que incluyan capacitación y psicoeducación basada en la resiliencia, acompañamiento emocional, así como la detección y referencia oportuna de casos, considerando tanto problemas de salud mental como de consumo de sustancias psicoactivas $s^{3-6}$.
- Generación de "Comité psicosocial interprofesional pandémico" que apoye y supervise la implementación de las medidas.

- Fortalecimiento y organización de servicios (sistemas de turnos y descansos, infraestructura, disponibilidad de Equipos de Protección Personal, etc.).

- Campaña de información actualizada y cercana a personal de la salud.

- Creación de espacios de encuentro y reflexión.

- Establecimiento de redes de colaboración con diversos actores para desarrollar las acciones (Sector Público, Colegios Profesionales, Organizaciones No Gubernamentales, Academia, otros)

- Diseño y entrega de recursos de apoyo psicológico.
- Capacitación a personal de salud y gestores.

- Apoyo decisiones éticas.

- Acompañamiento psicosocial.

- Durante la crisis: apoyo al autocuidado, resiliencia, primeros auxilios psicológicos.

Post crisis: foco en post-trauma, recuperación etc.

- Detección y derivación oportuna frente a problemas de salud mental/consumo de sustancias psicoactivas.

- Incorporación de apoyo a familiares.

- Intervención comunitaria sobre estigma y discriminación.

- Otras.

Figura 1. Abanico de Estrategias Disponibles para Reducir el Impacto de la Pandemia COVID-19 en la Salud Mental del Personal Sanitario. 
Es fundamental involucrar a quienes tienen responsabilidad de gestión en los establecimientos de salud, como supervisores y jefaturas directas ${ }^{3-5}$. Se requiere transparencia de información, así como el desarrollo de una nueva narrativa que busque promover prácticas de autocuidado, desde el aprendizaje, promoviendo la vinculación del equipo de apoyo psicosocial y los profesionales de la salud. Algunas de las recomendaciones concretas que debieran cumplir los directivos incluyen: (1) Comunicación efectiva, (2) Establecer, fomentar y monitorizar descansos durante y entre turnos, y rotar a trabajadores de posiciones de alto estrés a otras de bajo estrés, y (3) Asegurar la disponibilidad de equipos de protección personal (EPP). También debe considerarse la interacción sujeto-institución, buscando la construcción de capital humano y apoyar el desarrollo de habilidades técnicas para desempeñarse fuera del área de experticia inicial, de ser necesario.

Los principios de justicia y equidad laboral constituyen un pilar fundamental de la respuesta; la institución debe velar por un desempeño en condiciones adecuadas de seguridad y contención psicosocial ${ }^{3-6}$. De esta forma se promueve una cultura de apoyo laboral, vital para mantener la resiliencia de las y los profesionales en este período de crisis sanitaria. Se busca también generar espacios de reflexión que contribuyan a que posterior a la crisis se cuente con una perspectiva de esperanza más que únicamente una centrada en el trauma. En ese sentido, a nivel comunitario, es importante también la prevención del estigma y la discriminación al personal sanitario expuesto a COVID-19.

En este contexto, toma importancia el establecimiento de redes de trabajo conjuntas con colegios profesionales, sociedades académicas, organizaciones comunitarias y no gubernamentales con experiencia en intervención psicosocial. Actualmente, en Chile ya existen algunas propuestas de apoyo a profesionales, desde distintas instancias. Por lo que es posible establecer alianzas para implementar intervenciones en crisis, consejería y generar grupos de expertos para guiar y coordinar con autoridades sanitarias.

Si se logra contar con el apoyo institucional, social y emocional adecuado, así como la adopción de medidas de prevención y promoción de la salud mental para el personal de salud, puede generarse un proceso de "crecimiento", en el cual las y los profesionales podrían fortalecer su auto concepto, así como la percepción de habilidades y resiliencia. Para esto es fundamental desarrollar medidas antes, durante y después de la crisis, de corto, mediano y largo plazo.

Es necesario establecer acciones e intervenciones basadas en la evidencia seleccionadas y adaptadas a nuestro contexto sociohistórico y cultural, en la realidad del sistema de salud. Generar estrategias que permitan que las y los profesionales de la salud de nuestros servicios, tengan un espacio de trabajo que procure su bienestar físico, psíquico y social a fin de asegurar una cultura de trabajo digno para todo el personal y proveer el mejor cuidado a su salud mental.

Carolina Traub $b^{1, a}$, Jaime C. Sapag ${ }^{1,2,3, b}$ ${ }^{1}$ Departamentos de Salud Pública y Medicina Familiar, Escuela de Medicina, Facultad de Medicina, Pontificia Universidad Católica de Chile. ${ }^{2}$ Clinical Public Health Division, Dalla Lana School of Public Health, University of Toronto, Canada. ${ }^{3}$ WHO/PAHO Collaborating Centre for Addiction and Mental Health, Institute for Mental Health Policy Research, Centre for Addiction and Mental Health (CAMH), Ontario, Canada. ${ }^{a}$ Terapeuta Ocupacional, MPH. ${ }^{b}$ Médico, Médico Familiar-Adultos, MPH, PhD.

\section{Referencias}

1. Shah K, Kamrai D, Mekala H, Mann B, Desai K. Focus on Mental Health during the Coronavirus (COVID-19) Pandemic: Applying Learnings from the Past Outbreaks. Cureus. 2020; 12 (3): e7405. https://doi.org/10.7759/cureus.7405.

2. García-Iglesias JJ, Gómez-Salgado J, Martín-Pereira J, Fagundo-Rivera J, Ayuso-Murillo D, Martínez-Riera JR, et al. Impacto del SARS-Cov-2 (COVID-19) en la Salud Mental de los Profesionales Sanitarios: Una Revisión Sistemática. Rev Esp Salud Publica 2020; 94: e202007088.

3. Greenberg N, Docherty M, Gnanapragasam S, Wessely S. Managing Mental Health Challenges Faced by Healthcare Workers during Covid-19 Pandemic Early support. BMJ [Internet]. 2020; 1211 (March). Available from: http:// dx.doi.org/doi:10.1136/bmj.m1211.

4. Dewey C, Hingle S, LGoelz E, Linzer M. Supporting Clinicians During the COVID-19 Pandemic. Ann Intern Med. 2020; 172 (11): 752-3. doi: 10.7326/M20-1033.

5. Blake H, Bermingham F, Johnson G, Tabner A. Mitigating the Psychological Impact of COVID-19 on Healthcare Workers: A Digital Learning Package. Int J Environ Res Public Health 2020; 17 (9): E2997. doi: 10.3390/ijerph17092997.

6. OPS. Cuidando la Salud Mental del Personal Sanitario durante la Pandemia COVID-19. OPS, Junio, 2020. Disponible en: https://www.paho.org/es/documentos/ cuidando-salud-mental-personal-sanitario-durante-pandemia-covid-19-0.

Correspondencia a:

Jaime C. Sapag

Departamentos de Salud Pública y Medicina Familiar

División Salud Pública y Medicina Familiar

Escuela de Medicina, Facultad de Medicina Universidad Católica de Chile.

Diagonal Paraguay 362, Piso 2 (Salud Pública). Santiago, Chile. jsapag@med.puc.cl 